\title{
USO DO PADRAO MARC EM BIBLIOTECAS UNIVERSITÁRIAS DA REGIÃO SUL DO BRASIL ${ }^{1}$ USING THE STANDARD MARC BY UNIVERSITIES LIBRARIES OF SOUTH REGION OF BRAZIL
}

\author{
Gisele Vasconcelos Dziekaniak - giseledziekaniak@yahoo.com.br \\ Professora no Curso de Biblioteconomia da FURG, Rio Grande, RS. \\ Doutoranda no Programa de Pós-Graduação em Engenharia e Gestão do Conhecimento da \\ UFSC. \\ Líder no Grupo de Pesquisa Educação, Conhecimento e Tecnologia - EDUTEC \\ Jackson da Silva Medeiros - jacksonmedeiros@yahoo.com.br \\ João Paulo Borges da Silveira - jhonw_@hotmail.com \\ Maria Fermina Fortes - mariafermina@ig.com.br \\ Virgínia Oliveira Borges - virginiapjpel@hotmail.com \\ Acadêmicos do Curso de Biblioteconomia da FURG, membros do Grupo EDUTEC
}

\begin{abstract}
Resumo
Esta pesquisa objetivou analisar a utilização do padrão MARC (MAchine Readable Cataloging record) pelas bibliotecas universitárias que compreendem a Região Sul do Brasil, bem como se propôs a identificar o uso da interoperabilidade entre elas. Para tanto, baseou-se na hipótese de que, apesar das bibliotecas, ao escolherem um padrão de metadados para descreverem seus acervos, optarem, em sua maioria, pelo padrão MARC, tais bibliotecas não têm por principal objetivo a interoperabilidade. A pesquisa considera este recurso de grande importância porque através dele é possível manter a padronização de bases de dados, realizar a catalogação cooperativa, reduzir esforços e evitar o re-trabalho. Aborda vantagens no uso de protocolos de comunicação aliados a padrões de metadados. Quanto aos resultados, a pesquisa demonstrou que o Estado pesquisado que mais utiliza o padrão MARC é o Paraná (PR), onde 68\% das bibliotecas entrevistadas afirmam utilizá-lo; o Rio Grande do Sul (RS) é o Estado que menos utiliza o padrão, sendo usado por 60\% das bibliotecas respondentes. Quanto ao princípio da interoperabilidade pode-se perceber que o PR utiliza este recurso em cerca de $85 \%$ das bibliotecas respondentes, seguido de Santa Catarina, que interopera através do MARC em 66\% das bibliotecas respondentes. Considerando que a maioria das bibliotecas consultadas são informatizadas (usuárias de softwares gerenciadores de bibliotecas) e estes softwares possibilitarem (70\% deles) a realização da catalogação via padrão MARC, as bibliotecas universitárias da Região Sul do Brasil ainda realizam a interoperabilidade de maneira tímida; Como sugestão para amenizar esta baixa utilização e baixo aproveitamento de recursos do MARC a pesquisa concluiu que
\end{abstract}

\footnotetext{
${ }^{1}$ Esta pesquisa foi realizada pelo Grupo de Pesquisa Educação, Conhecimento e Tecnologia (EDUTEC), através do projeto vinculado ao Departamento de Biblioteconomia e História da FURG e credenciado pelo $\mathrm{CNPq}$; o grupo desenvolve pesquisas envolvendo a organização do conhecimento aliada às tecnologias de aplicação como os metadados e as ontologias e mantém suas atividades desde outubro de 2005.

Enc. Bibli: R. Eletr. Bibliotecon. Ci. Inf., Florianópolis, n. 26, 2º sem.2008
} 
o desenvolvimento de cooperativas entre bibliotecas seria uma das saídas para dividir despesas e lucros com o desenvolvimento de softwares que possibilitem a interoperabilidade e a padronização via uso do MARC.

Palavras-chave: Padrão MARC. Bibliotecas Universitárias. Interoperabilidade. Protocolo de comunicação Z39.50.

\section{INTRODUÇÃO}

As bibliotecas contemporâneas no Brasil, principalmente as universitárias e as de comunidades científicas especializadas, têm adotado padrões para representação descritiva de suas coleções, ou seja, padrões de metadados. Porém a Biblioteconomia ainda necessita de estudos que explorem tal utilização uma vez que, nem todas as bibliotecas utilitárias de padrões de metadados fazem uso dos recursos de interoperabilidade possibilitados por tais padrões.

Este artigo derivou de um projeto de pesquisa, através do qual se propôs avaliar e detectar a utilização do padrão de metadados MARC. A etapa seguinte inclui a promoção de discussões teóricas, bem como a mensuração e análise da utilização deste padrão pela comunidade biblioteconômica da Região Sul do Brasil (Rio Grande do Sul, Santa Catarina e Paraná), além da análise do processo da interoperabilidade entre bibliotecas, via softwares gerenciadores de bibliotecas.

Parte-se do princípio de que o estudo e o domínio teórico-prático acerca dos padrões de metadados utilizados pela comunidade biblioteconômica é de grande importância para a área, uma vez que os formatos de disseminação da informação modificaram-se com o amplo uso da Internet.

Além disso, os profissionais envolvidos com a Biblioteconomia passaram a necessitar de conhecimentos acerca da manipulação da informação em suportes eletrônicos. Isto a fim de aperfeiçoar os processos de tratamento e disponibilização organizados desta informação. Deste modo entende-se como inegável a necessidade da comunidade biblioteconômica discutir e testar padrões de metadados para o tratamento e disseminação dos acervos informatizados.

\subsection{Padrão de metadados: o MARC}

Um padrão, de acordo com a ISO (International Organization for Standardization) vem a ser "[...] um documento aprovado por um organismo reconhecido que provê, pelo uso comum e repetitivo, regras, diretrizes ou características de produtos, processos ou serviços cuja obediência não é obrigatória”. (ISO, 2006)

De acordo com Feitosa (2006, p. 51-2), no âmbito biblioteconômico um metadado "[...] pode ser considerado como dado estruturado, que compartilha diversas características similares para a catalogação, e que descreve as características de um determinado recurso informacional".

O MARC enquanto padrão de metadados possui os seguintes elementos: estrutura, designação de conteúdo e conteúdos dos dados, sendo que é sua estrutura que possibilita a

Enc. Bibli: R. Eletr. Bibliotecon. Ci. Inf., Florianópolis, n. 26, 2º sem.2008 
interoperabilidade, uma vez que ela possui implementação de padrões internacionais como a ANSI Z39.50: protocolo para comunicação de dados entre sistemas de informação.

Retomando um pouco da história do padrão MARC, tem-se no final dos anos 1950 a iniciativa da Library of Congress (LC) a qual começou a investigar sobre a possibilidade de automatizar suas operações. Entre os anos de 1965-66, após algumas conferências entre a LC e outros órgãos, como a Counsil on Library Resources (CLR), foi apresentado o padrão aberto de catalogação conhecido como MARC, criado pela LC, para padronizar a estrutura, o conteúdo e a codificação dos arquivos bibliográficos armazenados em fichas catalográficas e convertê-las para o meio legível por máquina, significando que um computador pudesse ler e interpretar a informação num registro bibliográfico, de modo a possibilitar o intercâmbio de registros entre bibliotecas.

Em linhas gerais o padrão MARC possibilita adicionar informações, definir campos para uso local, atualizar informações existentes, atribuir pontos de acesso recuperáveis e possibilita a catalogação cooperativa, flexibilizando o processo de catalogação, através da interoperabilidade.

\subsection{Interoperabilidade: conceito, importância e vantagens}

O intercâmbio desde há muito tempo é praticado pelas bibliotecas na busca de satisfazer as necessidades informacionais dos usuários quando a compra particular da obra não se faz possível. Primeiramente isto ocorria através do envio do documento físico por correio tradicional e posterior devolução mediante certo prazo, o que demandava muito tempo de espera e gerava custos.

Mais adiante essa troca de informação ocorria (e ainda ocorre) via COMUT on-line (Programa de Comutação Bibliográfica on-line), através do qual a obra não precisava mais se ausentar da biblioteca fornecedora, uma vez que o documento podia ser digitalizado e recebido via correio eletrônico pela biblioteca solicitante (ainda demandando custos).

Porém com a consolidação dos catálogos eletrônicos (OPACs ${ }^{4}$ ) além da utilização do mesmo padrão de catalogação, através do Anglo-American Cataloguing Rules (AACR2), se faz necessário o uso de um padrão legível por máquina, que estabeleça a relação entre as áreas presentes no AACR2 e, que estas sejam interpretadas pelo software utilizado pela biblioteca, para que ocorra a interoperabilidade eletrônica (modalidade a qual não gera custo procedimental).

Percebe-se que, do intercâmbio à interoperabilidade, com o advento das tecnologias aplicadas às bibliotecas, houve grande evolução, tanto no que diz respeito à minimização de custos quanto de tempo despendido com a tarefa de envio e recebimento do material. Esta atividade é facilitada quando bibliotecas utilizam o mesmo padrão de metadados como o MARC.

Paul Miller (2007 apud SAYÃO, 2007, p.39) diz que a "Interoperabilidade pode ser considerada como o processo de assegurar que sistemas, procedimentos e a cultura de uma organização sejam gerenciados de modo a maximizar as oportunidades para intercâmbio e reuso de informações.” Ou seja, passar a utilizá-la oportuniza economia no tratamento de informação otimizando a troca desta informação.

${ }^{4}$ OPAC é o acrônimo de Online Public Access Catalog - o qual vem a ser o catálogo on-line passível de consulta e que contém as informações catalográficas sobre o registro das obras presentes no acervo de uma biblioteca.

Enc. Bibli: R. Eletr. Bibliotecon. Ci. Inf., Florianópolis, n. 26, 2º sem.2008 
Sendo assim a interoperabilidade não depende apenas de requisitos técnicos; a plena interoperabilidade exige uma mudança freqüente na forma pela qual uma organização trabalha e se relaciona com as demais organizações parceiras, com os seus usuários e seus fornecedores. O objetivo da interoperabilidade, de acordo com Noerr (2003) vem a ser a tentativa de unificação e representação, além da manipulação ou a transmissão de algum item de informação, de maneira que sistemas de informação diferentes possam "entender" este item da mesma maneira.

O conceito de interoperabilidade está relacionado com a troca e compartilhamento de informações, oportunizando que bases de dados de diferentes instituições troquem dados, gerando assim a disseminação da informação de maneira ágil e eficaz, objetivo de todo sistema de informação.

Deste modo as bibliotecas usuárias de padrões de metadados, como o MARC, aliadas a protocolos de informação que facilitam a transferência de dados via sistemas com diferentes interfaces, dão um salto qualitativo no processo de disseminação da informação eletrônica. Esta não é a única utilidade do MARC, haja vista ele ser um padrão aceito internacionalmente, o que padroniza tanto a catalogação quanto à interoperabilidade.

\subsection{Protocolo e linguagem para comunicação: Z 39.50}

A necessidade informacional de pessoas e grupos requer agilidade e precisão no intercâmbio de informações. Nota-se, com certa facilidade, a concentração de esforços para que a troca de informações seja feita de forma rápida e segura, de modo a satisfazer a necessidade informacional do usuário. Segundo Rosseto (1997) a existência de uma necessidade de ordenação obriga o desenvolvimento de modelos para garantir os investimentos realizados pelos usuários ou fabricantes.

Protocolos são conjuntos de padrões convencionados que contém regras as quais permitem a comunicação entre sistemas computacionais; Essas convenções possibilitam a comunicação num ambiente de rede.

Uma das possibilidades desta troca de informação via sistemas é assegurada pelo protocolo Z39.50 que "faz a comunicação entre computadores [...] para permitir a pesquisa e recuperação de informação [...] entre redes de computadores distribuídos” (MOEN, 1995 apud ROSSETO, 1997, p. ). Isso, a partir da idéia da NISO (The National Information Standards Organization), permitiria a padronização no intercâmbio de dados, facilitando a recuperação dos mesmos. Esta padronização em sistemas desempenha papel fundamental na segurança e rapidez com que os dados são recuperados, uma vez que fornece à organização, a resposta necessária que será enviada após uma requisição pelo usuário.

Ainda segundo ROSSETO (1997), o protocolo Z39.50 pode ser utilizado independentemente da plataforma escolhida, promovendo a interoperabilidade entre os sistemas envolvidos na troca de informações sobre um determinado objeto, além de oferecer uma interface única para os usuários, fato que desonera o mesmo da necessidade de aprender a utilização de vários comandos.

Outra tecnologia que vem sendo utilizada é a XML (eXtensible Markup Language). Esta linguagem, de acordo com Santarém Segundo e Vidotti (2007) pode ser utilizada não só em ambientes digitais, mas também em bibliotecas tradicionais, contribuindo para o processo de transferência de dados (interoperabilidade), visto que o MARC, já existe em sua versão 
XML, o MARCXML. Este foi desenvolvido pela Library of Congress e, segundo estes autores ele "alia um formato coeso de descrição de registros bibliográficos com a versatilidade e interoperabilidade da linguagem XML”. Desta maneira as bibliotecas tradicionais já podem contar com mais esta possibilidade que antes era restrita somente ao ambiente digital e à internet.

Defende-se neste artigo a temática de utilização de padrões de metadados e de interoperabilidade sob o enfoque do uso de tecnologia livre, sob a premissa de que pouco adianta fazer uso de um padrão de metadados, se este não fizer parte de uma aplicação aberta. Ou seja, a interoperabilidade se presta muito bem quando os sistemas de informação são desenvolvidos em software livre.

Deste modo o ambiente se torna ainda mais colaborativo e útil uma vez que, além de possibilitar a importação/exportação de registros sem ônus, ele também é passível de ser desenvolvido com um baixo custo, devido ao software não ser proprietário e não exigir pagamento pelo seu uso.

Além do que, um padrão aberto possui uma maior aceitação, o que faz com que mais bibliotecas venham a utilizá-lo, efetivando ainda mais o seu uso. Outra vantagem é que sendo um padrão livre, comunidades contribuem para sua otimização, atualização e desenvolvem pesquisas na área, contribuindo assim para a evolução e utilidade do mesmo, bem como das áreas envolvidas.

\section{METODOLOGIA DA PESQUISA}

Em linhas gerais os passos seguidos na para realização desta pesquisa foram encontros semanais do grupo de pesquisa durante o ano de 2007; a elaboração da estrutura da pesquisa; a realização de leituras semanais e sua apresentação pelos membros do grupo acerca de artigos pertinentes à área de metadados; o fichamento dos artigos discutidos; a coleta de dados junto às bibliotecas da Região Sul (RS, SC e PR) a qual foi realizada via correio eletrônico, através de um questionário misto (com perguntas abertas e fechadas).

Após a coleta dos dados procedeu-se à tabulação dos mesmos e à sua análise, através dos objetivos da pesquisa cruzando-os com a literatura da área e a visão dos autores, tendo os resultados encontrados divulgados através deste artigo.

Quanto ao tipo de pesquisa a mesma é um estudo de caso, quali-quantitativo, tendo como cenário as bibliotecas universitárias da Região Sul. Para obter a relação das instituições de ensino superior (IES) da Região Sul do Brasil buscou-se na Internet, no site do MEC, através do Portal Sistema de Educação Brasileiro (SiedSup), também do Portal Terra no seu diretório Educação, bem como do Portal da Associação Catarinense das Fundações Educacionais (Rede ACAFE). Foi necessário recorrer a demais fontes, além do site do MEC, porque o mesmo não se encontrava atualizado quando da realização da pesquisa.

Considerando que o envio do instrumento de coleta foi realizado por correio eletrônico e que este dificulta a composição de uma amostra significativa, considerou-se que se atingiu um valor considerável para a identificação do cenário e do objeto da pesquisa. Dos 216 questionários encaminhados (algumas bibliotecas não possuíam website na internet e outras não possuíam informação de correio eletrônico, portanto não se conseguiu endereço eletrônico de todas elas), 78 questionários foram respondidos nas tentativas via e-mail, porém precisou-se encaminhar por até quatro vezes para instituições não respondentes e ainda assim houve ausências de entrega. 
Por conta disto o grupo realizou contato telefônico com muitas bibliotecas e conseguiu entrevistar mais 35 bibliotecários que não haviam respondido o questionário por e-mail. Através destas 2 modalidades de contato, a amostra da pesquisa foi composta por aproximadamente $45 \%$ das bibliotecas universitárias da Região Sul, o que não demonstra a totalidade das bibliotecas universitárias, porém evidencia o cenário de quase metade das bibliotecas universitárias da Região Sul.

\section{ANÁLISE DOS RESULTADOS}

Uma das preocupações quando da análise dos resultados da pesquisa foi verificar se as bibliotecas universitárias participantes faziam uso de softwares gerenciadores de bibliotecas que disponibilizassem o padrão MARC no módulo catalogação, uma vez que, se esses softwares não possibilitassem a catalogação em MARC, esse seria um dos fatores que dificultariam a interoperabilidade de registros entre bibliotecas, uma vez que estas necessitam do uso de um base tecnológica para conseguir catalogar em MARC e assim poder interoperar.

Para tanto a questão 4 do questionário dizia respeito ao software que as bibliotecas utilizavam e perguntava: "Qual o software de gerenciamento de bibliotecas sua instituição utiliza?” Após elaborar uma listagem com todos os softwares apontados por Estado, verificou-se no site dos fornecedores se os mesmos utilizavam o padrão MARC. Quanto a este fator identificou-se que $70 \%$ deles disponibilizam algum módulo ou aplicativo para catalogação no formato $\mathrm{MARC}^{6}$. Logo, este não é o principal motivo para que as bibliotecas universitárias da Região Sul do Brasil não interoperem.

Ainda assim, houve ocorrência de cerca de 15 softwares utilizados pelas bibliotecas que não eram compatíveis com o padrão MARC, índice considerado bastante negativamente significativo. Informatizar uma biblioteca deveria significar prover informações de maneira ágil e satisfatória ao usuário e isto é também conseguido através do intercâmbio de informações.

Porém vale dizer que a diversidade de softwares utilizados na Região Sul foi alta: cerca de 29 softwares no RS, em SC foram 10 softwares e no PR foram 14 softwares, sendo que 5 deles apareceram nos 3 Estados, denotando que os mesmos são bastante conhecidos e utilizados na Região. Destes 5 softwares mais utilizados nas bibliotecas da Região Sul, 3 deles são softwares proprietários, 1 é gratuito quando para mono-usuário e 1 deles é livre. Muitos softwares apontados foram considerados “caseiros”, ou seja, desenvolvidos pela própria universidade a qual sedia a biblioteca.

Esta categoria de software a qual se nomeou na pesquisa de "software caseiro" demonstrou, pelo menos na amostra analisada, que a interoperabilidade ficou prejudica em função destes sistemas serem desenvolvidos para uma única biblioteca, de maneira particular, sem projetar e prever a possibilidade/necessidade de relacionamento entre arquivos de outro sistema com outras bibliotecas, como o uso do padrão MARC juntamente com o uso de protocolos de comunicação possibilitaria.

\footnotetext{
${ }^{6}$ A questão 4 identificou o nome dos softwares utilizados pelas bibliotecas porém não os nomeou neste artigo porquanto este não era o objetivo do trabalho. O nome do software somente foi importante para que o grupo pudesse acessar o site do fornecedor e identificar a possibilidade do uso do MARC ou não pelas bibliotecas usuárias destes sistemas.
}

Enc. Bibli: R. Eletr. Bibliotecon. Ci. Inf., Florianópolis, n. 26, 2º sem.2008 
Esta observação também pode ser percebida através de respostas à questão 1 do questionário, a qual perguntava: “A biblioteca utiliza o padrão MARC para catalogação?” Para esta pergunta obteve-se respostas como: "o software que utilizamos não é compatível com o MARC", ou ainda em outra resposta "a biblioteca usa um sistema próprio de gerenciamento de coleções” (justificativas para a não utilização do padrão MARC).

Outra resposta chamou bastante a atenção pelo fato do bibliotecário dizer: "não o utilizo, pois o considero muito complexo, não conheço direito e nunca o usei". O que faz crer que um dos argumentos desta resposta invalida o outro, por conta de que, como pode o bibliotecário julgá-lo muito complexo se nunca o utilizou e afirma não conhecê-lo? Esta postura demonstra insegurança diante da tecnologia que não pode ser considerada nova para a área, apesar de terem ocorrido respostas à pergunta 1 que denotam ausência de conhecimento acerca deste padrão como: "não conheço o MARC".

Ainda quanto à utilização de softwares identificou-se dificuldade na negociação entre algumas bibliotecas e sua administração superior em relação à aquisição de ou ainda provisão de investimentos financeiros para o seu desenvolvimento (que realmente se proponham a gerenciar acervos ${ }^{7)}$.

Como sugestão a estas bibliotecas não possuidoras de autonomia para a seleção de um software de gerenciamento, devido principalmente ao seu alto custo, sugere-se a criação de cooperativas entre bibliotecas universitárias para o desenvolvimento de sistemas que contemplem as necessidades destas instituições, visando a padronização e a interoperabilidade. Considera-se esta opção além de ideal porque personalizada (porquanto que o sistema contemplaria as necessidades específicas destas bibliotecas, levando em consideração suas peculiaridades), viável financeiramente (uma vez que o custo seria dividido entre as instituições cooperantes).

Ocorreram respostas que identificaram bibliotecas em situação de começo do processo de informatização ao responderem que estão iniciando a cadastrar seus acervos em bases de dados como o Winisis, por exemplo. Quanto ao uso deste tipo de software, - apenas de cadastro e recuperação na base de dados -, seu uso corrobora para a ausência de interoperabilidade entre as bibliotecas, uma vez que não permite a padronização dos dados através da utilização de um modelo de metadados, como é o caso do MARC, além de limitar a gestão de uma biblioteca.

Para demonstração quantitativa do resultado da questão 1 tem-se o gráfico a seguir:

\footnotetext{
${ }^{7}$ Está se abordando a diferença entre softwares que possuem apenas módulo de cadastro e recuperação de registros, dos softwares completos para gerenciamento de bibliotecas, os quais contemplam desde o cadastro do acervo, recuperação de informação, circulação, administração, gerência de periódicos até a emissão de relatórios de diversos tipos e finalidades.

Enc. Bibli: R. Eletr. Bibliotecon. Ci. Inf., Florianópolis, n. 26, 2º sem.2008
} 


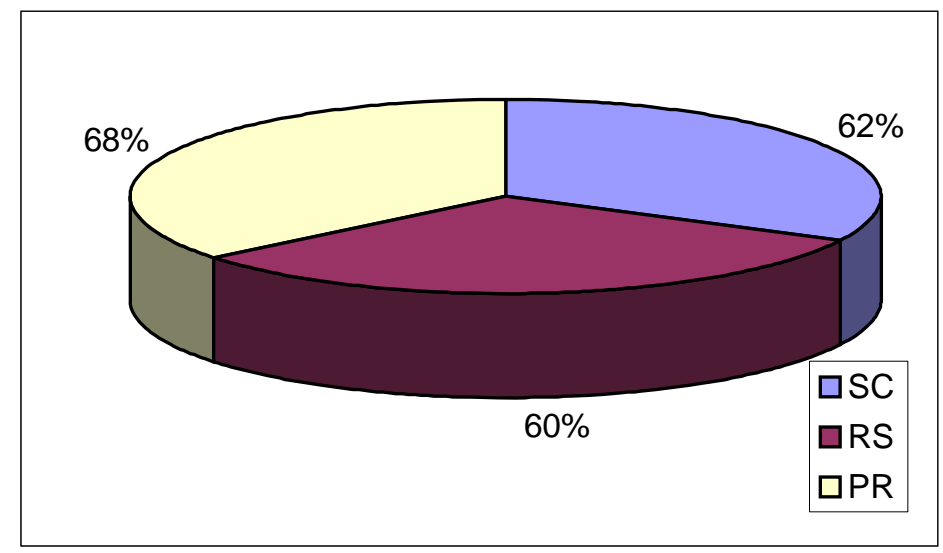

Figura 1: Uso MARC nas BUs da Região Sul do Brasil

A figura 1 demonstra que o PR é o Estado da Região Sul que mais utiliza o padrão MARC em bibliotecas universitárias. Apesar do RS ser o Estado a obter a menor colocação quanto à categoria "uso do padrão", o Estado de SC igualmente possui baixa utilização do MARC em suas bibliotecas, conforme se pode analisar no gráfico. Considera-se que este percentual de uso poderia ser maior.

A média de uso do padrão na Região Sul é de apenas 63\%, o que denota um baixo uso do padrão de metadados mais utilizado no mundo todo para interoperar dados entre sistemas de informação para gerenciamento de bibliotecas (porém não na internet, ambiente no qual o padrão de metadados mais difundido é o Dublin Core).

Com relação à questão 2 do questionário, que perguntava: "Caso sim [utiliza o padrão MARC] realizam intercâmbio de registros com alguma biblioteca? Qual(s)?” Através das respostas obtidas detectou-se que o Paraná é o Estado da Região Sul que mais utiliza o padrão MARC para realizar a interoperabilidade de registros, entre os Estados consultados; sendo realizada por $85 \%$ das bibliotecas entrevistadas. Santa Catarina aparece em segundo lugar, fazendo uso da interoperabilidade por $66 \%$ das bibliotecas entrevistadas. O Rio Grande do Sul aparece na terceira posição, interoperando em 61\% de suas bibliotecas. A média geral de uso da interoperabilidade entre os Estados pesquisados foi de 74\%, indicando um bom índice de interoperabilidade entre as bibliotecas na Região Sul do país na amostra analisada ${ }^{8}$.

Apesar de muitas bibliotecas informarem que interoperam, apenas $40 \%$ disseram com que bibliotecas o fazem (mesmo ao ser perguntado). O que leva a considerar a possibilidade de alguma biblioteca ter respondido sem saber realmente o significado do termo interoperabilidade, já que a pergunta 2 era bastante objetiva.

Como a aplicação do questionário se deu por e-mail, em sua maioria, tal consideração pode ser entendida como mera especulação da parte dos pesquisadores, sugerindo a necessidade de uma análise mais profunda e da retomada do contato com as bibliotecas que não

\footnotetext{
8 Quanto aos dados de média de uso do MARC (63\%) e de realização de interoperabilidade (74\%) em um primeiro momento pode confundir levando a crer que houve informações distorcidas porém cabe ressaltar que o resultado envolvendo a interoperabilidade é relativa aos que usam o MARC e interoperam através dele.
}

Enc. Bibli: R. Eletr. Bibliotecon. Ci. Inf., Florianópolis, n. 26, 2ºm.2008 
informaram os parceiros. Situação que se tornou impossibilitada até o momento, devido ao tempo previsto para conclusão da pesquisa.

Ainda quanto à categoria "interoperabilidade" detectou-se as principais modalidades utilizadas pelas bibliotecas. Este fenômeno ocorre principalmente entre bibliotecas universitárias da mesma universidade (entre as bibliotecas setoriais e sua central), entre bibliotecas usuárias de um mesmo software, as quais formam uma rede (por exemplo, a Rede Pergamum) e entre as bibliotecas universitárias e fundações como a Fundação Getúlio Vargas (FGV) e até mesmo a Library of Congress, esta com menor ocorrência.

A fim de detectar os principais motivos pelos quais as bibliotecas ao utilizarem o MARC não interoperam, perguntou-se na questão 3: "Caso utilizam o padrão MARC mas não interoperam, qual o motivo?". Para esta questão houve respostas como: "porque a biblioteca usa um sistema próprio de gerenciamento de coleções” (consulente no PR) e ainda: "o software que utilizamos não é compatível com o padrão MARC” (consulente em $\mathrm{SC})$.

Entende-se através destas e de outras respostas que, os principais motivos para o uso do MARC sem interoperar é o fato de que muitas bibliotecas acreditam usar o MARC, mas na realidade não o fazem haja vista que todo software desenvolvido com base no MARC teoricamente deve permitir a importação e exportação de registros em MARC.

Chama-se atenção ao fato de que há sistemas comerciais que informam utilizar o MARC, porém o que oferecem nada mais é do que uma máscara para as áreas do AACR2 em rótulo MARC (ou seja, ao invés do rótulo autor o sistema trás, por exemplo, o rótulo 100, para o título, o rótulo 245, e assim por diante. Porém nada possuem de relação com o padrão MARC a não ser a representação dos rótulos dos campos não permitindo a importação/ exportação de registros via sistema porque não utilizam indicadores e sub-campos).

Outra resposta à questão 3 , de um consulente no RS que utiliza o padrão MARC chamou bastante atenção: "não interopero porque não julgo necessário". Mas então fica o questionamento, para que catalogar em MARC, haja vista a especificidade e o nível que este padrão exige na inserção dos dados de um registro, se o bibliotecário não utiliza seu recurso que oferece um agregar de valor ao processo de catalogação que é a interoperabilidade?

A questão 5 a qual abordava: "Você acredita ser vantajoso o uso do padrão MARC? Por quê?" e tinha o objetivo de identificar se os bibliotecários compreendiam a interoperabilidade como uma possibilidade metodológica positiva e se sabiam que o MARC facilita este processo obteve respostas como: "[...] porque podemos usar de catalogação compartilhada, transferência de informação, facilitando nosso dia-a-dia e minimizando tempo.” (bibliotecário do RS).

Outra resposta obtida nesta questão foi: "sem padrões não teríamos como saber onde localizar as informações para descrição física de línguas diversas.” (consulente do RS), outra resposta: "[...] para intercambiar dados" (consulente do PR), ou mesmo: "Sim, porque o MARC é eficiente na descrição uniforme dos dados facilitando a recuperação da informação" (consulente do SC), outro consulente do RS disse que o uso do MARC : "facilita...o bibliotecário pode dedicar-se a outras tarefas" - provavelmente se referindo à possibilidade de interoperabilidade - , e outro disse que é: “[...] porque é um padrão internacional (consulente do SC).

Pode-se perceber que a interoperabilidade está presente em muitas das respostas, evidenciando que, embora muitas bibliotecas não interoperem, ainda assim julgam 
importante fazê-la e conseguem identificar os motivos desta importância entendendo o padrão MARC como aliado neste processo.

A respeito da padronização, cabe destacar que sua importância é evidente, porém é preciso levar em conta que em padrões como o MARC torna-se possível estabelecer critérios para esta padronização, ou seja, há campos no MARC que possibilitam uma especificação de dados acerca de registros de uma biblioteca, os quais não precisam ser utilizados pelas demais com as quais mantém intercâmbio, oportunizando assim um uso amplo e padronizado e ao mesmo tempo personalizado, protegendo e conservando as peculiaridades das bibliotecas usuárias.

\section{CONSIDERAÇÕES FINAIS}

Pode-se inferir sobre muitas categorias ao analisar as respostas coletadas e tecer cruzamentos interessantes entre elas, como conhecimento acerca da interoperabilidade e a possibilidade de, a padronização de dados com uso do MARC, a relação software e catalogação em MARC, o conhecimento teórico-prático sobre padrões de metadados, a tipologia de softwares (proprietários, livres ou gratuitos e o uso do MARC), a realidade financeira das BU's da Região Sul, o investimento em tecnologia por elas, dentre outras não menos importantes. Sendo que foram estas as categorias nas quais se baseou a análise, por compreender que são as mais representativas para o cenário da interoperabilidade na Região no momento.

Através da análise identificou-se que muitas das bibliotecas que interoperam, o fazem por conta da facilidade propiciada pelo software gerenciador da biblioteca e estão atreladas à participação destas bibliotecas em alguma rede e muitas destas redes são de usuários do mesmo software - sendo estes softwares o elo entre as bibliotecas, como uma força exógena, vinda de fora destas bibliotecas, empurrando-as rumo à interoperabilidade, antes mesmo dos bibliotecários se darem conta de sua importância e exigirem esta possibilidade dos fornecedores de softwares.

Outra interpretação passível de ser feita é quanto às bibliotecas não utilizarem softwares desenvolvidos em MARC e não interoperarem. Por não utilizarem o MARC ficam de fora do processo de interoperabilidade, uma vez que este padrão “foi escolhido" pela comunidade de bibliotecas do Brasil (e do mundo) para promover a padronização dos dados e, conseqüentemente oportunizar uma interoperabilidade segura. Isto foi percebido quando bibliotecas informaram que utilizam softwares caseiros tanto na pergunta 1 (a biblioteca utiliza o padrão MARC para catalogação?) quanto na pergunta 4 que perguntava acerca do software utilizado pela biblioteca.

Identificou-se conflito de terminologia ou ausência de conhecimento acerca da teoria da interoperabilidade e de padrões de metadados como o MARC por alguns bibliotecários entrevistados, uma vez que houve respostas que apontaram distorções entre o que vem a ser o padrão MARC e um software para biblioteca, demonstrando que, para alguns, ambos são a mesma coisa, quando não o são: “...não uso o padrão MARC uso outro software para biblioteca, ele foi desenvolvido pela instituição", e ainda sobre ausência de conhecimento teórico sobre interoperabilidade: "Não sei o que vem a ser intercâmbio de dados".

Pode-se perceber que há uma heterogeneidade muito grande entre a realidade das bibliotecas universitárias da Região Sul. Desde diferenças na condição financeira (condição de aquisição de um software proprietário ou mesmo desenvolver um sistema "caseiro"

Enc. Bibli: R. Eletr. Bibliotecon. Ci. Inf., Florianópolis, n. 26, 2º sem.2008 
requer investimento financeiro considerável) até diferenças no nível de conhecimento por parte de seus bibliotecários acerca de interoperabilidade e padrões de metadados como o MARC (alguns bibliotecários informaram desconhecer o padrão MARC, fato que prejudica a utilização da interoperabilidade e a padronização de registros em bases de dados).

Algumas bibliotecas universitárias da Região Sul do Brasil ainda encontram-se em processo de implementação de tecnologias de informação e comunicação. Sendo realidade desde o cadastro de acervo em fase inicial, - por conta de software recém adquirido, ou por conta de troca de software -, entre elas bibliotecas de instituições consideradas jovens (menos de 5 anos de criação) e outras nem tanto (mais de 15 anos).

Com base nas discussões realizadas neste espaço entende-se que a temática acerca da importância do uso de um padrão de metadados e da interoperabilidade entre bibliotecas mereceria tornar-se mais discutida e ampliada através de pesquisas nas demais Regiões do país. A fim de identificar o cenário nacional com relação a esta temática tão pertinente denotada por grandes semelhanças e diferenças conceituais e práticas em que se encontram as bibliotecas universitárias brasileiras.

\section{LIMITAÇÕES E DIFICULDADES ENCONTRADAS NO DESENVOLVIMENTO DA PESQUISA}

Toda pesquisa possui limitações no seu desenvolvimento, e com esta não foi diferente. Acredita-se pertinente abordá-las para que outros pesquisadores ao tratarem da mesma temática, ou utilizarem metodologia semelhante, saibam de alguns dos obstáculos que poderão enfrentar.

Além da ausência de recursos financeiros - mazela presente na maioria dos projetos de pesquisa desenvolvidos por docentes de universidades com titulação de Mestre - os quais mesmo possuindo ampla produção científica em sua área de atuação, não possuem crédito suficiente para concorrer a bolsas de fomento à pesquisa por órgãos brasileiros - outros fatores limitaram e dificultaram o desenvolvimento desta pesquisa.

Dentre as limitações cita-se: o site do MEC, órgão oficial do Governo Federal, estava desatualizado no momento da coleta da listagem de IES, o que obrigou a consulta a outros sites para complementar os dados faltantes; muitos dos sites das IES não possuíam informações sobre as suas bibliotecas para realização do contato $^{8}$; inclusive algumas IES nem mesmo possuem link para a biblioteca, o que é um ponto falho a ser corrigido por elas, ao se considerar a biblioteca como um dos órgãos mais importantes para o ensino e pesquisa em uma universidade.

Houve dificuldade para entrar em contato com alguns bibliotecários por motivos como: ausência de bibliotecário na biblioteca por conta de que muitas delas, infelizmente, adotam a figura do bibliotecário itinerante, o qual visita a biblioteca cerca de 15 em 15 dias; houve a ocorrência de biblioteca em obra e de biblioteca em férias coletivas e também nos sites de algumas bibliotecas as informações estavam desatualizadas, ocasiões em que os e-mails retornaram com destinatário inválido. Obviamente nestas ocorrências as bibliotecas não responderam ao questionário, sendo estes os fatores principais do índice de resposta.

\footnotetext{
${ }^{8}$ Este fato foi evidenciado anteriormente por DZIEKANIAK, et al. (2006) em pesquisa que detectou lacunas nos websites de universidades e de bibliotecas da Região Sul, publicado na Revista Biblos, Rio Grande, v.19, 2006.

Enc. Bibli: R. Eletr. Bibliotecon. Ci. Inf., Florianópolis, n. 26, 2º sem.2008
} 


\title{
REFERÊNCIAS
}

FEITOSA, Ailton. Organização da informação na web: das tags à web semântica. Brasília: Briquet de Lemos, 2006.

HAIGH, Susan. A glossary of digital library: standards, protocols and format. Libraries and Archives. Canada, 1998. Disponível em: <http://www.collectionscanada.ca/9/1/p1253-e.html>. Acessado em 23 outubro de 2007.

ISO - INTERNATIONAL ORGANIZATION FOR STANDARDIZATION. Overview of the ISO System. ISO, 2006. Disponível em:

$<$ http://www.iso.org/iso/en/aboutiso/introduction/index.html\#one >. Acessado em 23 outubro de 2007.

NOERR, Peter. The Digital Library Toolkit. Sun Microsystems. 3 rd edition. Santa Clara, CA.: Sun Microsystems, January 2003. Disponível em:

$<$ http://www.sun.com/products-nsolutions/

edu/whitepapers/pdf/digital_library_toolkit.pdf >. Acessado em 04 maio 2007.

ROSSETO, Márcia. Uso do protocolo Z39.50 para recuperação de informação em redes eletrônicas. Ciência da Informação, v. 26, n. 2, 1997. Disponível em:

$<$ http://www.ibict.br/cienciadainformacao/include/getdoc.php?id=752\&article=430\&mode =pdf $>$. Acesso em: 16 jul. 2007.

ROWLEY, J. Biblioteca eletrônica. 2. ed. Brasília: Briquet de Lemos, 2002.

SANTAREM SEGUNDO, José Eduardo; VIDOTTI, Silvana A. B. G. A linguagem XML como ferramenta facilitadora no processo estrutural de comunicação científica no formato digital. In: CONGRESSO BRASILEIRO DE BIBLIOTECONOMIA, DOCUMENTAÇAO E CIÊNCIA DA INFORMAÇÃO, 22.. Brasília, 2007. Anais... Brasília, 2007.

SAYÃO, Luís Fernando. Padrões para bibliotecas digitais abertas e interoperáveis. Enc. Bibli: R. Eletr. Bibliotecon. Ci. Inf., Florianópolis, n. esp., $1^{\circ}$ sem. 2007. Disponível em: <www.periódicos.ufsc.br/index.php/eb> . Acesso em: 20 jan. 2008.

\begin{abstract}
This study aimed to examine the use of standard MARC (MAchine Readable Cataloging record) by university libraries that comprise the Southern region of Brazil, and is proposed to identify the use of interoperability. Therefore, based on the assumption that, despite the libraries, to choose a standard metadata to describe their collections, choosing, in the main, by default MARC such libraries do not have the primary goal is interoperability. The study considers this feature of great importance because through it is possible to maintain the standardization of databases, implement the cooperative cataloguing, reduce efforts and
\end{abstract}

Enc. Bibli: R. Eletr. Bibliotecon. Ci. Inf., Florianópolis, n. 26, 2º sem.2008 
avoid the re-work. It advantages in the use of communication protocols combined with patterns of metadata. As for results, the survey showed that the state searched that most uses standard MARC is the Paraná (PR), where $68 \%$ of libraries surveyed say use it, the Rio Grande do Sul (RS) is the state that uses the least default, being used by $60 \%$ of respondents libraries. The principle of interoperability you can see that the PR uses this feature in about $85 \%$ of libraries respondents, followed by Santa Catarina, which exports and import through MARC in 66\% of the respondents libraries. Considering that most libraries are consulted computerized (users of software managers libraries), and these make software ( $70 \%$ of them) the completion of cataloguing via standard MARC, the university libraries of the South Region of Brazil still hold the interoperability of a timid; As suggestion to alleviate this low utilization and low utilization of resources from the search MARC concluded that the development of cooperatives among libraries would be one of the exits to split expenses and profits with the development of software enabling the interoperability and standardization via use of MARC.

KEYWORDS: MARC standard. Universities libraries. Interoperability. Communication protocol Z39.50.

Originais recebidos em: 04/04/2008

Texto aprovado em: 02/09/2008

Enc. Bibli: R. Eletr. Bibliotecon. Ci. Inf., Florianópolis, n. 26, 2º sem.2008 